Science, Technology and Development 34 (3): 179-188, 2015

ISSN 0254-6418 / DOI: 10.3923/std.2015.179.188

(C) 2015 Pakistan Council for Science and Technology

\title{
Remote Sensing and GIS Applications for Assessment of Urban Sprawl in Karachi, Pakistan
}

\author{
Muhammad Ahsan Mahboob, Iqra Atif and Javed Iqbal \\ Institute of Geographical Information Systems, National University of Sciences and Technology, \\ Islamabad, Pakistan
}

\begin{abstract}
Over the past 30 years, Land development and consumption have been out of control and expanding out of order, especially to marginal areas of some metropolises in Pakistan. In this research, the dynamic change of urban sprawl and its spatial and temporal characteristics was analyzed for Karachi division, Pakistan. To achieve the goal different image processing techniques were applied i.e., (i) Supervised, (ii) Unsupervised image classification and (iii) Normalized Difference Built-Up Index on Landsat imageries for the years 1991, 2000 and 2013. Unsupervised classification technique was proved to be more effective with an overall agreement of $81 \%$. The study concluded that from 1991-2000, the urbanization in Karachi was increased from $486-729.2 \mathrm{~km}^{2}$, whereas from $2000-2013$ the urbanization was almost double i.e., $1582.5 \mathrm{~km}^{2}$. Apart from the derived results, this study also proved the potentials of remote sensing data and effectiveness of demonstrated/proposed techniques in urban geographic studies.
\end{abstract}

$\underline{\text { Key words: Remote sensing, GIS, image processing, urban sprawl mega city Pakistan, change detection }}$

\section{INTRODUCTION}

Urban sprawl is outward spreading of a city and its suburbs to exurbs, to low-density and often autodependent development on rural land (Gillham and MacLean, 2002). The rapid urbanization is usually caused by the increase in population in an area. The extent of urbanization or its growth drives the change in land use/cover pattern. Land use and landcover changes may have adverse impacts on ecology of the area, especially the greenness (Herold et al., 2003; Liu and Lathrop Jr., 2002; Grimm et al., 2000). Precise information on the extent of urban growth is of great interest for the municipalities of growing urban and suburban areas for diverse purposes such as urban planning, water and land resource management, marketing analysis, service allocation, etc. Development authorities are required to give more time, attention and effort to manage the use of land and other resources to accommodate the expanding population.

But unfortunately, the conventional surveying and mapping techniques are expensive and time consuming for the estimation of urban sprawl and such information is not available for most of the urban centers, especially in developing countries. As a result, increased research interest is being directed to the mapping and monitoring of urban sprawl/growth using GIS and remote sensing techniques (Goetz, 2013).
Remote sensing is cost effective and technologically sound, so is increasingly used for the analysis of urban sprawl (Carlson, 2003; Bhatta et al., 2010; Radhakrishnan et al., 2014; Mahboob et al., 2015). For nearly three decades, extensive research efforts have been made for urban change detection using remotely sensed images (e.g., Yang et al., 2001; Zhao et al., 2013; Ji et al., 2006; Yang and Lo, 2002; Ward et al., 2000; Lv et al., 2012; Hallum, 1993; Luo et al., 2008; Yuan et al., 2005; Weng, 2001; Chowdhury et al., 2009). These studies have been supported through either an image-to-image comparison or a post-classification comparison.

Statistical techniques along with remote sensing and GIS have been used in many urban sprawl studies (Malinverni, 2011; Lo and Choi, 2004; Weng, 2012; Cheng and Masser, 2003; Lu et al., 2008, Taubenbock et al., 2012; Sun et al., 2013). Urban growth studies have been attempted in several developed countries (Hu et al., 2003; Radhakrishnan et al., 2014; Sudhira et al., 2004; Triantakonstantis and Stathakis, 2015). These are some examples and similar applications also exist for other countries like China (Yu and Ng, 2007; Weng, 2001; Xiao et al., 2006) and India (Rahman et al., 2011; Taubenbock et al., 2009). The convergence of GIS and database management systems has helped in quantifying, monitoring, modelling and

\footnotetext{
Corresponding Author: Muhammad Ahsan Mahboob, Institute of Geographical Information Systems, School of Civil and Environmental Engineering, National University of Sciences and Technology, Islamabad, Pakistan Tel: 92-51-9085-4491/92-333-670-4571
} 
subsequently predicting the urban sprawl phenomenon. Characterizing urban sprawl pattern involves detection and quantification with appropriate scales and statistical summarization. Appropriate scale of urban sprawl characterization is the suitable spatial unit used in such analysis.

The study was conducted to analyze the dynamics of urban sprawl by using the remote sensing and GIS techniques. Largest division of Pakistan was selected, where urbanization would be hazard if not properly managed. Temporal window of 20 years ranging from 1991-2013 was considered to examine the spatial variation in urban sprawl of Karachi division and to establish the relationship between urban development and some its causative factors, like population, population density, density of built-up. Maximum Likelihood Classifier (MLC) approach was used for landsat image classification to inspect the spatial variability of urban sprawl as well as other land covers like water, vegetation, barren land.

\section{MATERIALS AND METHODS}

Study area: The study area for this research is Karachi division which is an administrative division of the Sindh Province of Pakistan as shown in Fig. 1. The Karachi division was abolished in 2000 and five districts of
Karachi were merged in City District Karachi. The City District Karachi was divided in 18 Towns and 178 union councils. On 11 July, 2011 Sindh Government restored again 5 districts of Karachi division.

Total Area of Karachi is 3,527 $\mathrm{km}^{2}$ and it is located at $24.8600^{\circ} \mathrm{N}, 67.0100^{\circ} \mathrm{E}$.

Data used: The data was collected from primary data source include Survey Of Pakistan (SOP) topo-sheets of Karachi (scale, 1:50,000) and multi-spectral Landsat MSS, TM, ETM+sensors. The data collected from secondary sources include the administrative boundary map. The details are given in Table 1 .

Methodology: Understanding the dynamic phenomenon, such as urban sprawl/growth, requires land use change analyses, urban sprawl pattern identification. The ERDAS (Leica) and ArcGIS software (ESRI) was used to generate various thematic layers, like, Karachi administrative boundary map, roads, railways network and administrative boundary map using the topo-sheets and other available maps. Complete methodology has been given in Fig. 2.

The standard image processing techniques, such as image extraction, rectification, restoration and classification was used for the analysis of three satellite images (1991, 2000 and 2002). The ERDAS imagine software was used for image analysis. First of

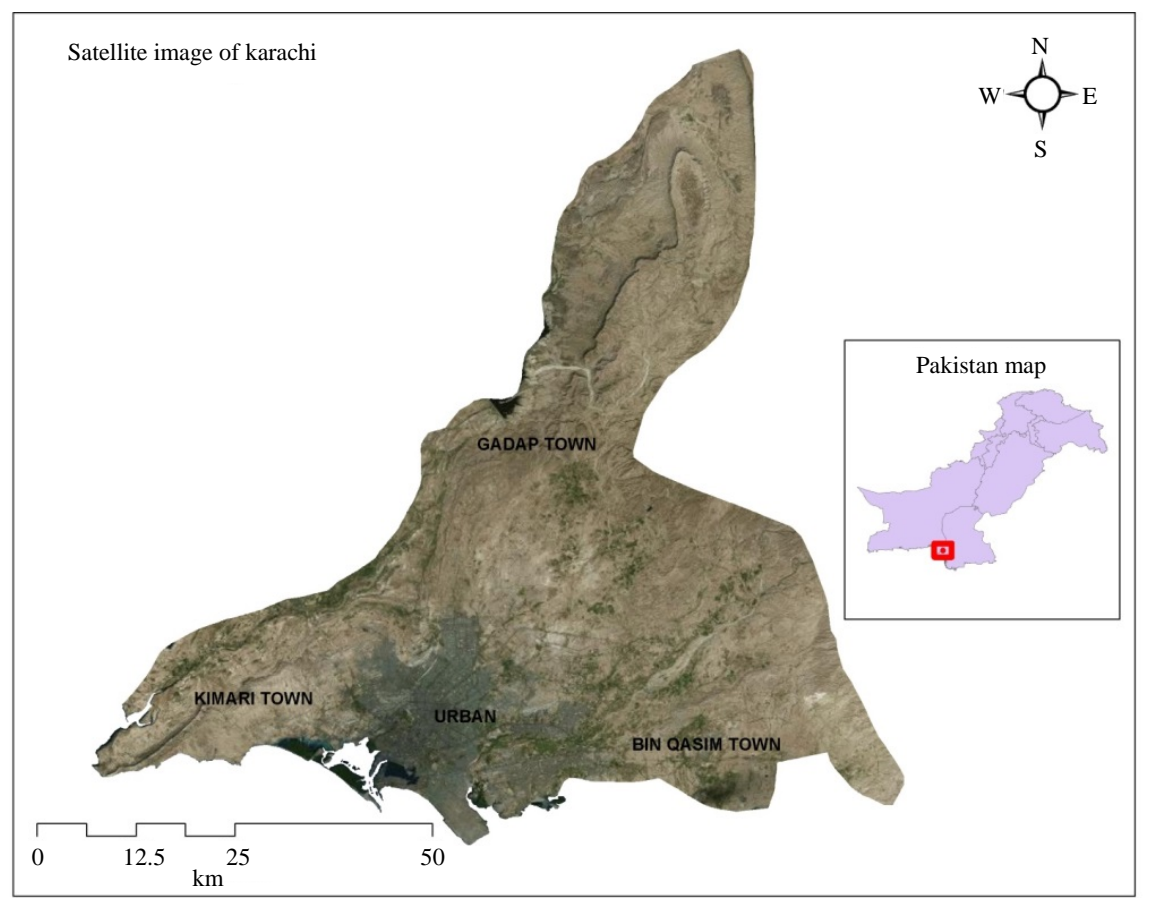

Fig. 1: Location map of study area: the Karachi division 


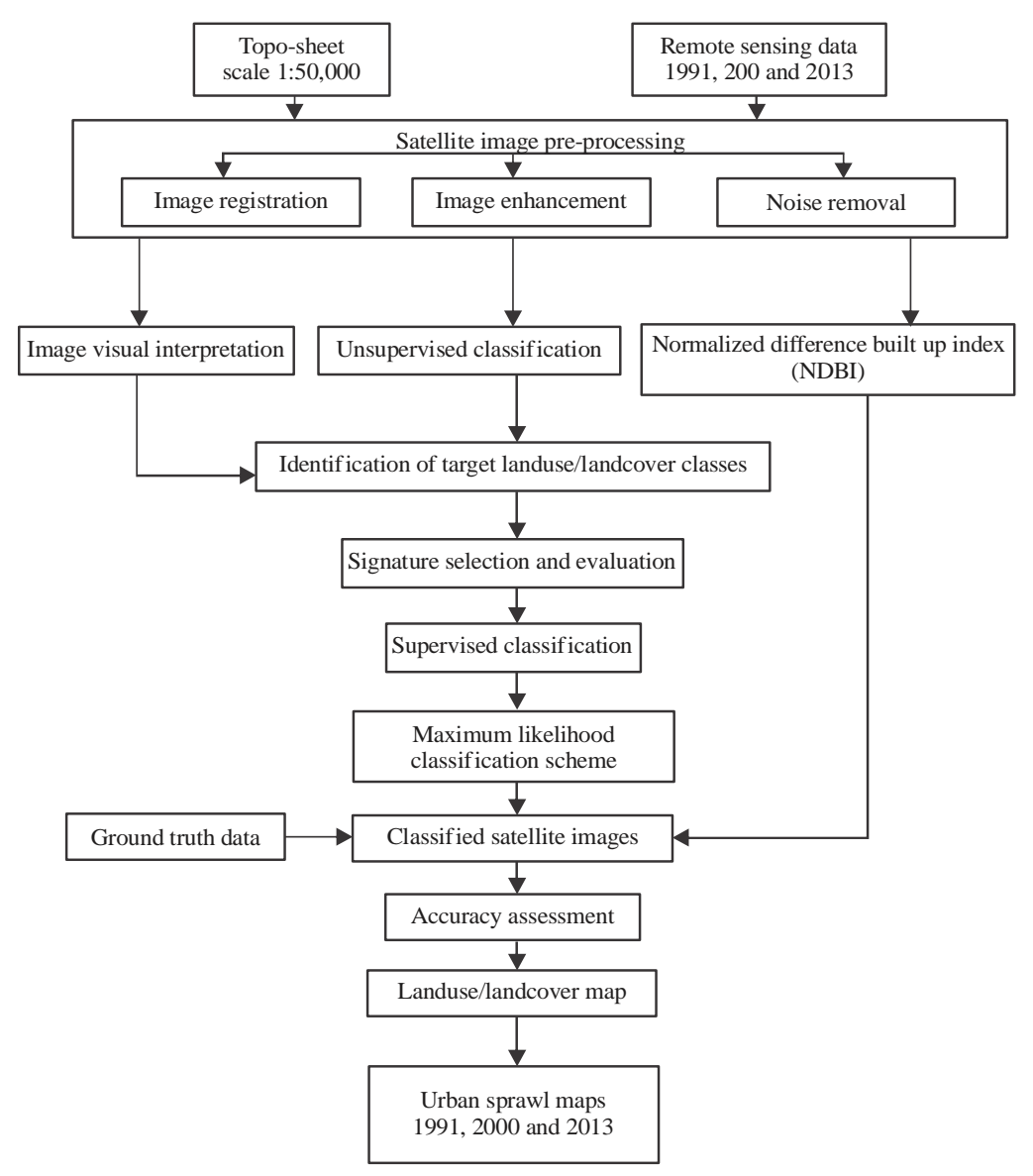

Fig. 2: Flowchart of methodology
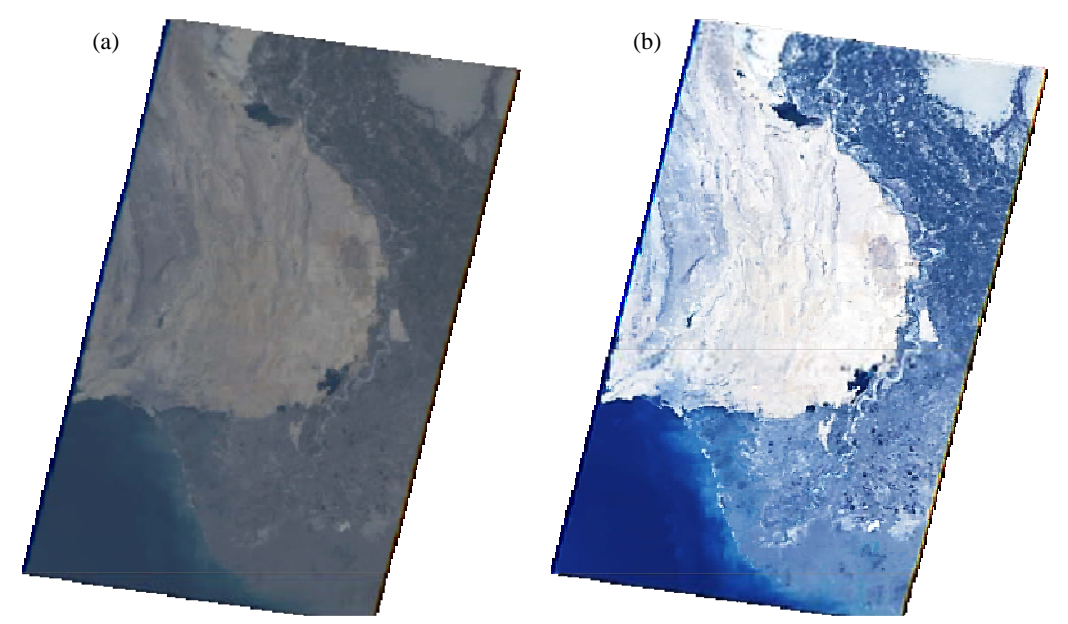

Fig. 3(a-b): Effect of image enhancement and correction, (a) Before and (b) After satellite image

all, atmospheric correction was applied using improved dark object subtraction method to bring all the images at common reference spectral characteristics. Water bodies available in the areas were used as the dark object. Further, these subtracted images were stretched to 8 bit digital number range. As an example, the Fig. 3 shows the before 3(a) and after 3(b) satellite image correction. 
Sci. Technol. Dev., 34 (3): 179-188, 2015
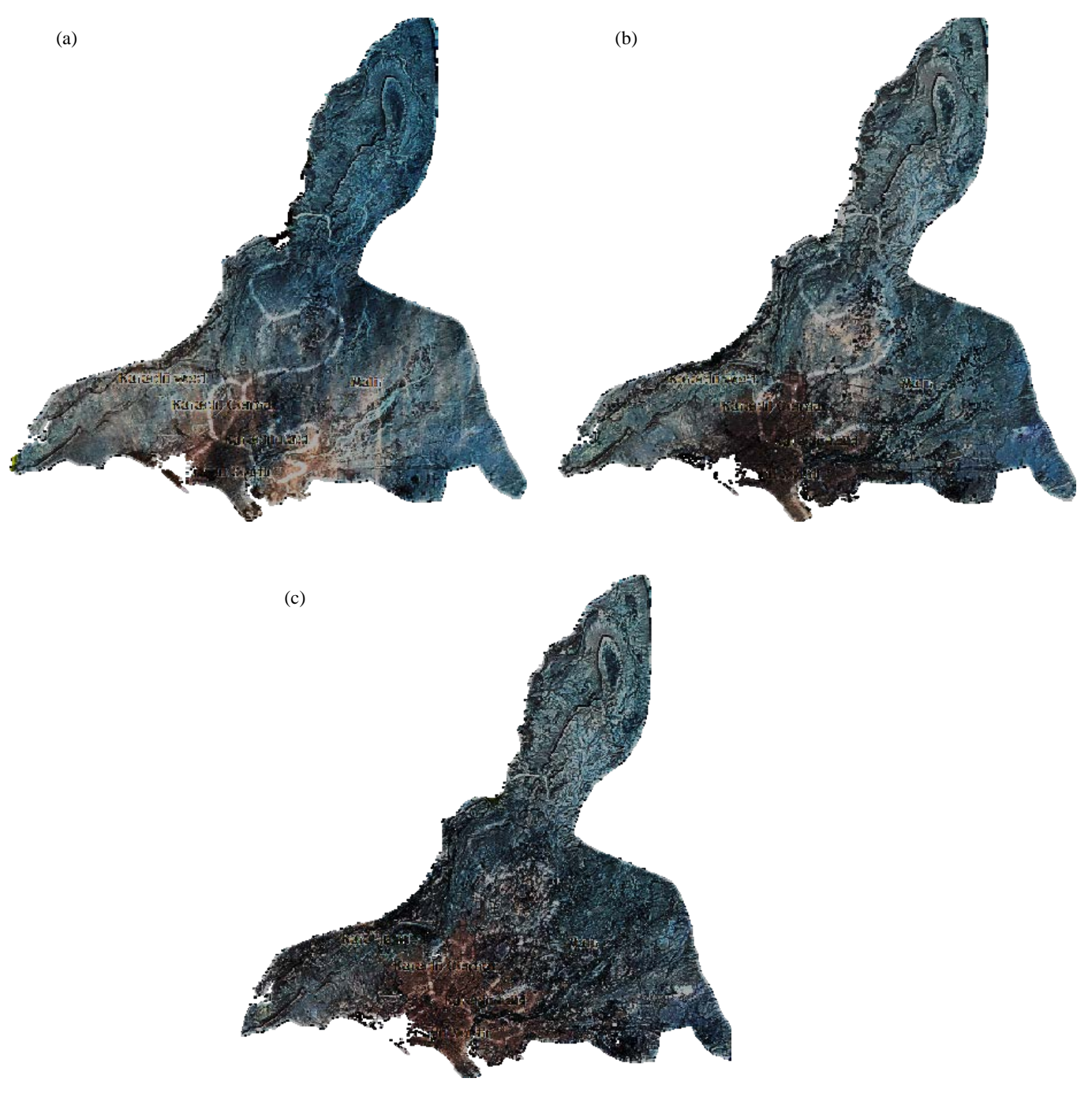

Fig. 4(a-c): Subset of satellite images for year (a) 1991, (b) 2000 and (c) 2013

Table 1: Different type of data used

\begin{tabular}{lll}
\hline Type of data used & Scale/resolution & Years \\
\hline Survey of Pakistan topo-sheets & $1: 50,000$ & $1995-96$ \\
Landsat TM image & $30 \mathrm{~m}$ & 1991 \\
Landsat TM image & $30 \mathrm{~m}$ & 2000 \\
Landsat ETM+ image & $30 \mathrm{~m}$ & 2013 \\
Administrative boundary map & $1: 25,000$ & 1990 \\
\hline
\end{tabular}

Further, the subset of each year was developed by using the administrative boundary of Karachi division as shown in Fig. 4. Satellite images were studied thoroughly to determine the probable land use classes. Spectral profiles was drawn to determine the separability and relative difference in pixel values of different land use classes in different spectral bands. Five separable land use classes was identified, such as barren land, water, vegetation, built up and mixed class, etc., Initially, supervised classification using MLC algorithm was performed for the classification of various images. To enhance the classification accuracy, knowledge-based expert system was used for post-classification refinement of initially classified outputs.

Then, the accuracy assessment of classified images is performed using ground truth data. More than 100 points for each year are collected and finally an error matrix is generated.

Also a parallel technique normalized difference built-up index (NDBI) is applied which is a popular image processing technique. This technique/algorithm is used to extract the built-up areas automatically from the satellite imagery. This index highlights urban areas where there is typically a higher reflectance in the shortwave-infrared (SWIR) region, compared to the Near-infrared (NIR) region. The equation of NDBI is given as under: 


$$
\mathrm{NDBI}=\frac{(\mathrm{SWIR}-\mathrm{NIR})}{(\mathrm{SWIR}+\mathrm{NIR})}
$$

NDBI was originally developed for use with Landsat TM bands 5 and 4. However, it will work with any multispectral sensor with a SWIR band between 1.55-1.75 $\mu \mathrm{m}$ and a NIR band between 0.76-0.9 $\mu \mathrm{m}$.

All these techniques i.e., supervised, unsupervised image classification and NDBI, are applied to map extract and map the urban sprawls over the period of almost twenty years.

\section{RESULTS AND DISCUSSION}

By using remote sensing and GIS techniques, urban sprawl of Karachi were identified. Both supervised and unsupervised image classification techniques were applied. The results show that there is a significant increase in urbanization.

Detecting urban growth using supervised classification: The classification of the satellite images into built-up and non-built-up areas for three temporal instants was resulted in the creation land cover of Karachi division (Fig. 5), which define the urban extents of specified times. The results show that over the period of time the barren land decreased, whereas the built-up area had been increased significantly.

The major urban sprawls is on North-West side i.e., towards Kemari Town and Gadap Town.

The square kilometer area graphical information is given in Fig. 6.
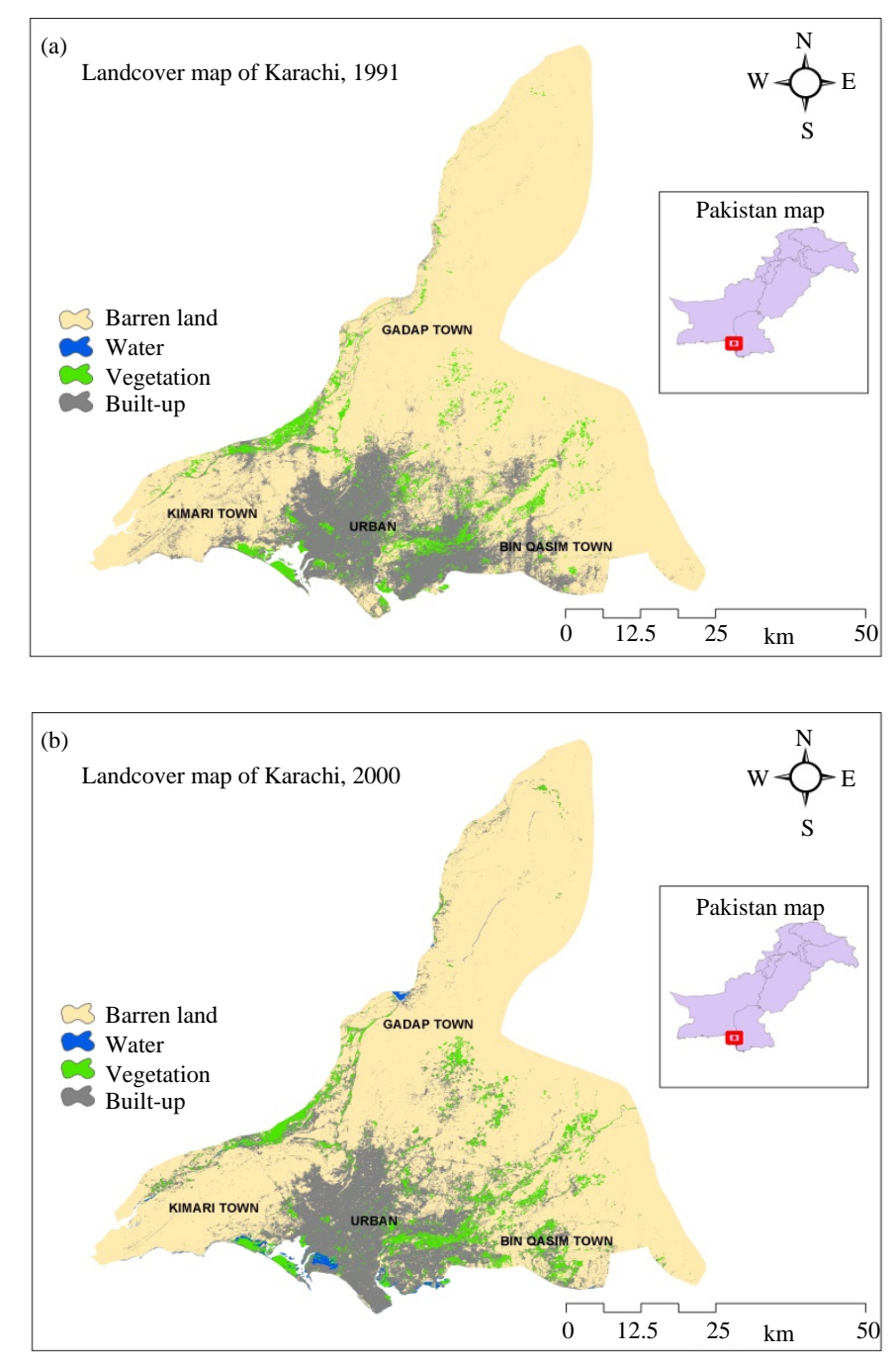

Fig. 5(a-c): Continue 


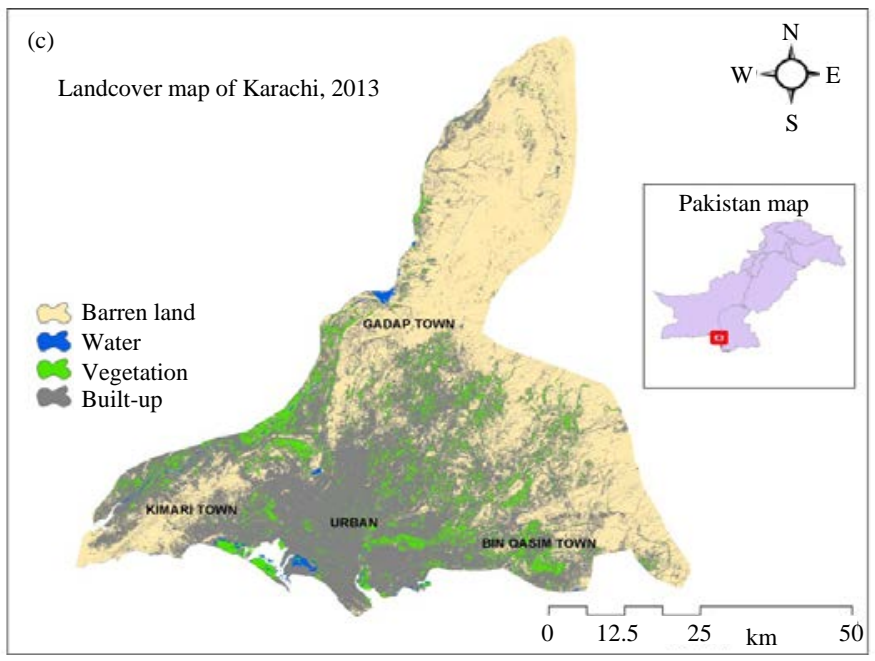

Fig. 5(a-c): Landcover maps of Karachi, (a) 1991, (b) 2000 and (c) 2013 division as per supervised classification technique

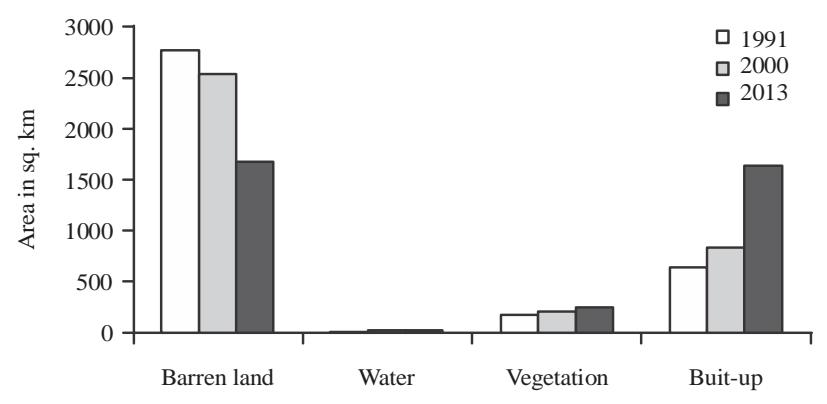

Fig. 6: Area in sq. km of landcover of Karachi division as per supervised classification technique

The overall accuracy of supervised classified images of Karachi division for year 1991, 2000 and 2013 is 70,76 and $74 \%$, respectively.

Detecting urban growth using unsupervised classification: The second method to classify satellite images into built-up and non-built-up areas is unsupervised classification. The same three temporal instants was resulted in the creation land cover of Karachi division (Fig. 7), which define the urban extents of specified times. The results show that over the period of time the barren land decreased whereas the built-up area had been increased significantly.

The unsupervised classification also shows that the major urban sprawls are on North-West side i.e., towards Kemari Town and Gadap Town. The square kilometer area graphical information is given in Fig. 8.
The overall accuracy of unsupervised classified images of Karachi division for year 1991, 2000 and 2013 is 79,81 and $83 \%$, respectively.

\section{Detecting urban growth using normalized} difference built-up index (NDBI): The built-up area of Karachi division is also extracted using NDBI technique for year 2013 as shown in Fig. 9. The results show that NDBI was overestimated the built-up area as per actual value. The overall accuracy of NDBI of Karachi division for year 2013 is $54 \%$, which means that the results of NDBI cannot be used with high confidence.

The overall urban sprawl of Karachi division for year 1991, 2000 and 2013 is shown in Fig. 10. It clearly indicates that Karachi division is expanding in an irregular way and most of the extension is towards West-North region. 
Sci. Technol. Dev., 34 (3): 179-188, 2015
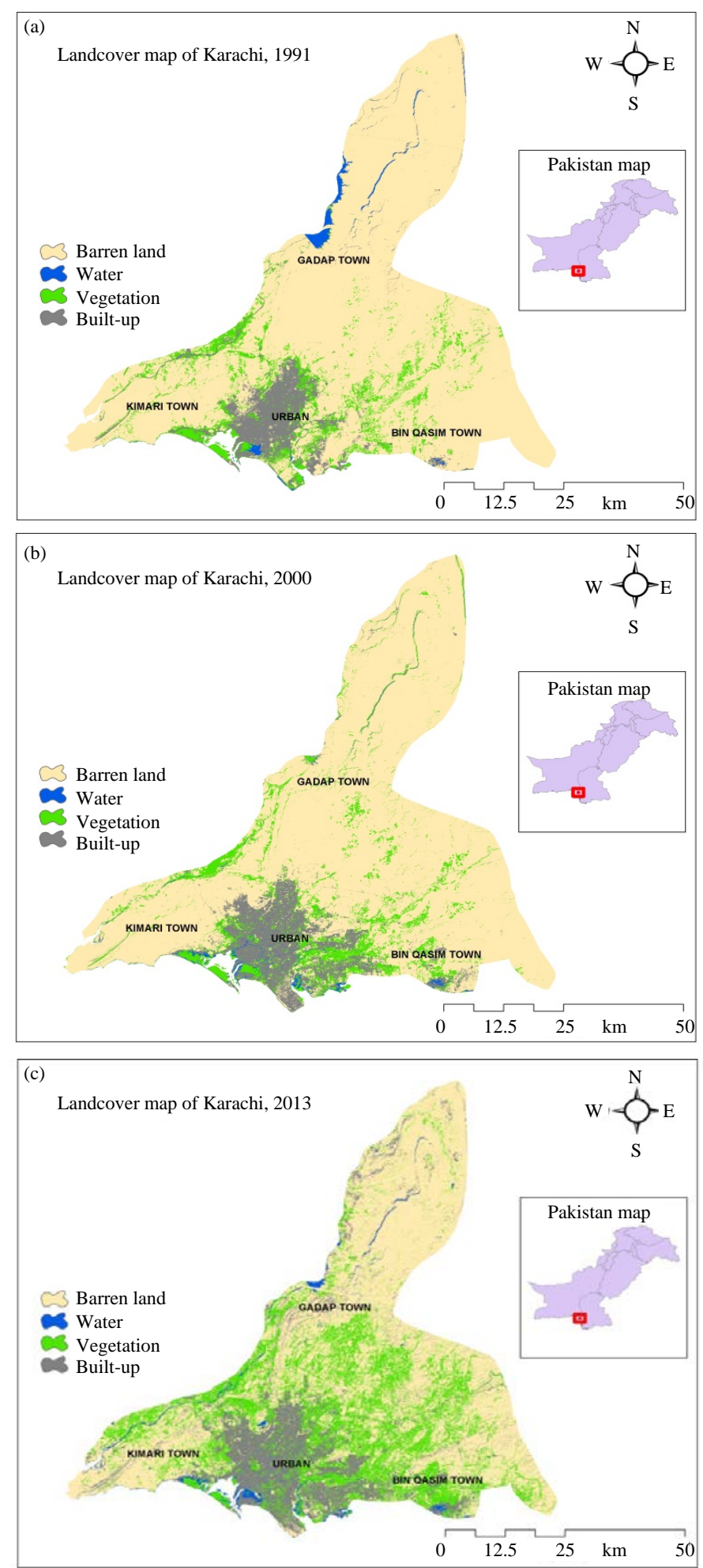

Fig. 7(a-c): Landcover maps of Karachi division, (a) 1991, (b) (2000) and (c) 2013 as per unsupervised classification technique 
Sci. Technol. Dev., 34 (3): 179-188, 2015

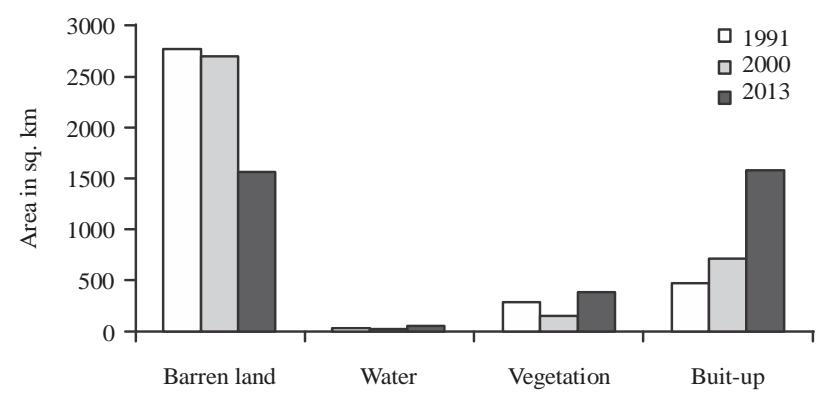

Fig. 8: Area in sq. km of landcover of Karachi division as per unsupervised classification technique

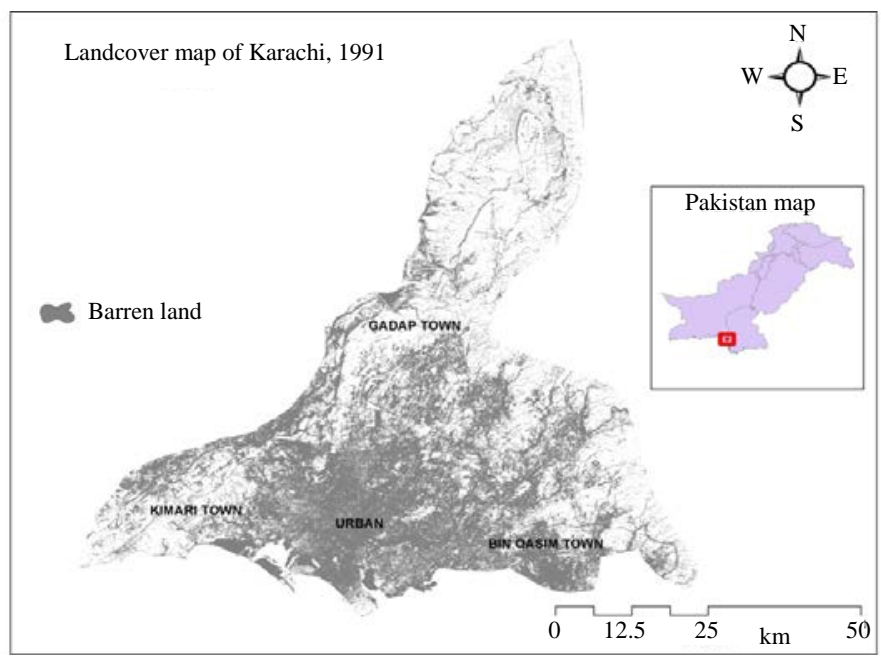

Fig. 9: Built-up map of Karachi division as per normalized difference built-up index technique

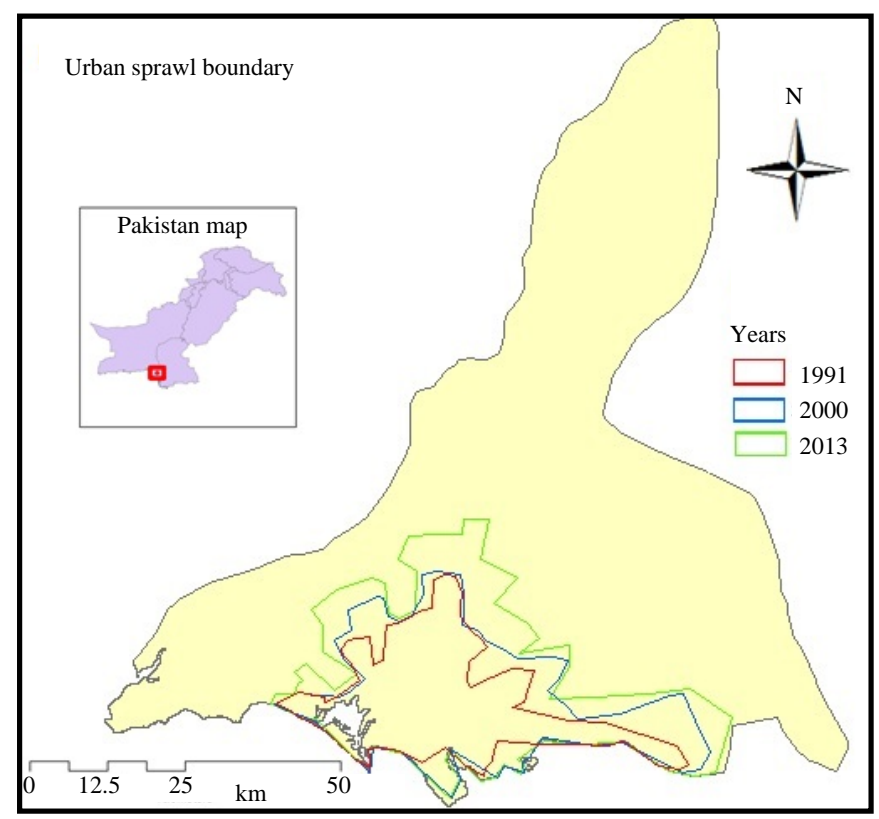

Fig. 10: Urban sprawl boundaries for year 1991, 2000 and 2013 
Sci. Technol. Dev., 34 (3): 179-188, 2015

\section{CONCLUSION}

The urban sprawl is seen as one of the potential challenge to sustainable development where urban planning with effective resource utilization, allocation of natural resources and infrastructure initiatives are key concerns. The study was aimed to analyze the urban growth of Karachi division from remote sensing data with three different techniques. Unsupervised classification technique proves to be more effective and accurate as compare to supervised and NDBI techniques.

In the future, the spatio-temporal modeling of urban sprawl may be done and will help us to better understand the evolved urban patterns of Karachi division.

Remote sensing technology is essential for dealing dynamic phenomenon, like urban sprawl. Without remote sensing data and GIS analysis, one may not be able to monitor and estimate the urban sprawl effectively over a time period, especially for elapsed time period.

\section{ACKNOWLEDGMENTS}

The authors would like to thank Mr. Asjad for his assistance in collection and processing data. We would also like to thank the National University of Sciences and Technology for providing all administrative support for completing this research.

\section{REFERENCES}

Bhatta, B., S. Saraswati and D. Bandyopadhyay, 2010. Urban sprawl measurement from remote sensing data. Applied Geogr., 30: 731-740.

Carlson, T., 2003. Applications of remote sensing to urban problems. Remote Sens. Environ., 86: 273-274.

Cheng, J. and I. Masser, 2003. Urban growth pattern modeling: A case study of Wuhan city, PR China. Landsc. Urban Plann., 62: 199-217.

Chowdhury, A., M.K. Jha, V.M. Chowdary and B.C. Mal, 2009. Integrated remote sensing and GIS based approach for assessing groundwater potential in West Medinipur district, West Bengal, India. Int. J. Remote Sens., 30: 231-250.

Gillham, O. and A.S. MacLean, 2002. The Limitless City: A Primer on the Urban Sprawl Debate. 1st Edn., Island Press, Washington, DC., USA., ISBN-13: 978-1559638333, Pages: 328.

Goetz, A., 2013. Suburban sprawl or urban centres: Tensions and contradictions of smart growth approaches in Denver, Colorado. Urban Stud., 50: 2178-2195.
Grimm, N.B., J.G. Grove, S.T. Pickett and C.L. Redman, 2000. Integrated approaches to long-term studies of urban ecological systems: Urban ecological systems present multiple challenges to ecologistspervasive human impact and extreme heterogeneity of cities and the need to integrate social and ecological approaches, concepts and theory. BioScience, 50: 571-584.

Hallum, C., 1993. A change detection strategy for monitoring vegetative and land-use cover types using remotely-sensed, satellite-based data. Remote Sens. Environ., 43: 171-177.

Herold, M., N.C. Goldstein and K.C. Clarke, 2003. The spatiotemporal form of urban growth: Measurement, analysis and modeling. Remote Sens. Environ., 86: 286-302.

Hu, J., S. You and U. Neumann, 2003. Approaches to large-scale urban modeling. IEEE Comput. Graph. Applic., 23: 62-69.

Ji, W., J. Ma, R.W. Twibell and K. Underhill, 2006. Characterizing urban sprawl using multi-stage remote sensing images and landscape metrics. Comput. Environ. Urban Syst., 30: 861-879.

Liu, X. and R.G. Lathrop Jr., 2002. Urban change detection based on an artificial neural network. Int. J. Remote Sens., 23: 2513-2518.

Lo, C.P. and J. Choi, 2004. A hybrid approach to urban land use/cover mapping using Landsat 7 Enhanced Thematic Mapper Plus (ETM+) images. Int. J. Remote Sens., 25: 2687-2700.

Lu, D., H. Tian, G. Zhou and H. Ge, 2008. Regional mapping of human settlements in Southeastern China with multisensor remotely sensed data. Remote Sens. Environ., 112: 3668-3679.

Luo, J., D. Yu and M. Xin, 2008. Modeling urban growth using GIS and remote sensing. GISci. Remote Sens., 45: 426-442.

Lv, Z.Q., F.Q. Dai and C. Sun, 2012. Evaluation of urban sprawl and urban landscape pattern in a rapidly developing region. Environ. Monit. Assess., 184: 6437-6448.

Mahboob, M.A., J. Iqbal and I Atif, 2015. Modeling and simulation of glacier avalanche: A case study of gayari sector glaciers hazards assessment. IEEE Trans. Geosci. Remote Sens., 53: 5824-5834.

Malinverni, E.S., 2011. Change detection applying landscape metrics on high remote sensing images. Photogramm. Eng. Remote Sens., 77: 1045-1056.

Radhakrishnan, N., S.K. Eerni and S. Kumar, 2014. Analysis of urban sprawl pattern in Tiruchirappalli city using applications of remote sensing and GIS. Arabian J. Sci. Eng., 39: 5555-5563. 
Rahman, A., S.P. Aggarwal, M. Netzband and S. Fazal, 2011. Monitoring urban sprawl using remote sensing and GIS techniques of a fast growing urban centre, India. IEEE J. Sel. Top. Applied Earth Observ. Remote Sens., 4: 56-64.

Sudhira, H.S., T.V. Ramachandra and K.S. Jagadish, 2004. Urban sprawl: Metrics, dynamics and modelling using GIS. Int. J. Applied Earth Observ. Geoinform., 5: 29-39.

Sun, C., Z.F. Wu, Z.Q. Lv, N. Yao and J.B. Wei, 2013. Quantifying different types of urban growth and the change dynamic in Guangzhou using multi-temporal remote sensing data. Int. J. Applied Earth Observ. Geoinform., 21: 409-417.

Taubenbock, H., M. Wegmann, A. Roth, H. Mehl and S. Dech, 2009. Urbanization in India-spatiotemporal analysis using remote sensing data. Comput. Environ. Urban Syst., 33: 179-188.

Taubenbock, H., T. Esch, A. Felbier, M. Wiesner, A. Roth and S. Dech, 2012. Monitoring urbanization in mega cities from space. Remote Sens. Environ., 117: 162-176.

Triantakonstantis, D. and D. Stathakis, 2015. Examining urban sprawl in Europe using spatial metrics. Geocarto Int., (In Press). 10.1080/10106049.2015.1027289

Ward, D., S.R. Phinn and A.T. Murray, 2000. Monitoring growth in rapidly urbanizing areas using remotely sensed data. Prof. Geogr., 52: 371-386.

Weng, Q., 2001. A remote sensing? GIS evaluation of urban expansion and its impact on surface temperature in the Zhujiang Delta, China. Int. J. Remote Sens., 22: 1999-2014.
Weng, Q., 2012. Remote sensing of impervious surfaces in the urban areas: Requirements, methods and trends. Remote Sens. Environ., 117: 34-49.

Xiao, J., Y. Shen, J. Ge, R. Tateishi, C. Tang, Y. Liang and Z. Huang, 2006. Evaluating urban expansion and land use change in Shijiazhuang, China, by using GIS and remote sensing. Landscape Urban Plan., 75: 69-80.

Yang, S., Y. Zha and J. Gao, 2001. Applications of remote sensing and GIS to monitoring of urban sprawl: A case study in Wuxi City, China. Geogr. Inform. Sci., 7: 137-141.

Yang, X. and C.P. Lo, 2002. Using a time series of satellite imagery to detect land use and land cover changes in the Atlanta, Georgia metropolitan area. Int. J. Remote Sens., 23: 1775-1798.

Yu, X.J. and C.N. Ng, 2007. Spatial and temporal dynamics of urban sprawl along two urban-rural transects: A case study of Guangzhou, China. Landsc. Urban Plann., 79: 96-109.

Yuan, F., K.E. Sawaya, B.C. Loeffelholz and M.E. Bauer, 2005. Land cover classification and change analysis of the Twin Cities (Minnesota) Metropolitan Area by multitemporal Landsat remote sensing. Remote Sens. Environ., 98: 317-328.

Zhao, J.L., D.Y. Zhang, H. Yang and L.S. Huang, 2013. Monitoring of rapid urban sprawl in Beijing with time series remote sensing data and analysis of driving forces. Adv. Mater. Res., 726-731: 4591-4595. 